\title{
Presença do tema ética profissional nos periódicos brasileiros de Ciência da Informação e Biblioteconomia ${ }^{1}$
}

Francisco das Chagas de Souza

\begin{abstract}
Doutor em Educação. Docente do Programa de Pós-Graduação em Ciência da Informação e do Curso de Graduação em Biblioteconomia - UFSC. Coordenador do Grupo de pesquisa Informação, Tecnologia e Sociedade
\end{abstract}

Katiusa Stumpf

\begin{abstract}
Bolsista de Iniciação Científica - PIBIC/UFSC Curso de Graduação em Biblioteconomia.
\end{abstract}

A presença de discussões acerca de temas relativos à Ética na produção científica brasileira de Biblioteconomia e Ciência da Informação é o enfoque principal deste texto, que advém da análise de periódicos desses campos de conhecimento e da prática profissional. Para isso, selecionou-se um título por cada região políticoadministrativa brasileira, Sul, Sudeste, Centro-Oeste e Nordeste, dentre os existentes, cuja edição tivesse se mantido regular no período de 1997 a 2006. Em cada um desses títulos, a partir de palavras-chave previamente definidas, foram identificados os artigos e ensaios que trataram do tema. Com isso, buscava-se conhecer os fundamentos filosóficos e doutrinários, as temáticas e abordagens, e as tendências da discussão Ética na produção periódica brasileira de Biblioteconomia e Ciência da Informação. Metodologicamente, o trabalho envolve a identificação dos periódicos e dos textos publicados sobre a temática; a leitura e a descrição dos mesmos; a identificação dos aspectos apontados nos objetivos pretendidos; a análise dos discursos utilizando a técnica do Discurso do Sujeito Coletivo; e a organização das idéias contidas visando chegar a uma síntese. Foram localizados 10 textos produzidos por 16 autores, sendo dois de 1997, quatro de 2005, quatro distribuídos de

\footnotetext{
${ }^{1}$ Elaborado com base nos resultados da pesquisa "Ética e deontologia profissional nos periódicos brasileiros de Ciência da Informação e Biblioteconomia, de 1997 a 2006", desenvolvida no âmbito do PIBIC/CNPq/UFSC $2007 / 8$.
} 
1998 a 2004; nenhum foi encontrado referente ao ano de 2006. Foram identificadas como fundamentos éticos as Doutrinas da Ética do Discurso, da Ética da Alteridade e da Teoria Ético-política da Justiça; e foram também identificadas as temáticas, abordagens e tendências da discussão sobre a Ética, que revelaram a questão da postura profissional determinada pelo quadro atual da sociedade e das tecnologias. Conclui-se que apesar de existir preocupação com o tema Ética por parte de alguns profissionais da informação que escrevem e publicam sobre o assunto, o mesmo ainda é pouco explorado na literatura e está mais dirigido para questões gerais.

Palavras-chave: Ética e Biblioteconomia; Ética Profissional; Discurso Ético; Produção Científica.

\section{Presence of professional ethics issue in Brazilian journals of Information Science and Librarianship}

The presence of discussions on issues relating to ethics in Brazilian scientific production of Librarianship and Information Science is the main focus of this text, which comes from the periodic review of these fields of knowledge and professional practice. For this reason, picked up a scientific periodical title for each brazilian administrative region, whose editing had been maintained regularly over the period 1997 to 2006. In each of these periodical titles, from keywords previously defined, have been identified articles and essays which addressed the theme. With this, trying to be informed of the reasons for philosophical and doctrinal, the themes and approaches and trends of the discussion Ethics in regular production of Brazilian Librarianship and Information Science. Methodologically, the work involved identification of journals and texts published on the subject, reading and description of them; identification of the aspects highlighted in the objectives pursued, analysis of speech using the technique of Discurso do Sujeito Coletivo collective subject of discourse) - DSC; organization of the ideas contained, aiming to reach a synthesis. We found 10 texts produced by 16 authors, 2 of 1997, 4 in 2005, 4 distributed from 1998 to 2004 and none was found regarding the year 2006. They were identified as ethical foundations, the doctrines of Ethics of Speech, the Ethics 
of Otherness and Ethical-Political Theory of Justice, in addition to the issues, approaches and trends of the discussion Ethics, which show the issue of professional attitude determined by the current picture of society and current technologies. We conclude that although there is concern about the ethics issue by some of the professionals who write and publish information on the subject, it is still little explored in literature and is more focused on general issues.

Keywords: Ethics and Librarianship; Professional Ethics; Ethical speech; Scientific Production.

Recebido em 12. 12. 2008 Aceito em 04.12.2009

\section{Introdução}

Este artigo insere-se no contexto dos estudos sobre ética profissional bibliotecária no Brasil, ora em desenvolvimento no Departamento de Ciência da Informação da UFSC. Nesta etapa da pesquisa, estudou-se a presença do tema Ética profissional nos periódicos brasileiros de Ciência da Informação e Biblioteconomia. Partiu-se da noção de que este tema constitui objeto de interesse da produção científica brasileira de Biblioteconomia e Ciência da Informação. A ética profissional trata de um fenômeno relevante por sua inserção no conjunto das práticas profissionais cotidianas de um contingente expressivo de profissionais, nas suas relações com os usuários reais e potenciais, e com os não-usuários dos serviços de informação, fornecidos ou não em bibliotecas.

O objetivo inicialmente pretendido foi o de conhecer os fundamentos filosóficos e doutrinários, as temáticas e abordagens e as tendências da discussão Ética na produção periódica editada no período de 1997 a 2006. $O$ entendimento que deu base à escolha desse decênio tinha em vista um quadro sócio-psicológico repleto de esperanças e assombrado pelo desconhecido. Nesse decênio, houve a transição entre duas décadas, dois séculos e dois milênios. Essa transição esteve cercada por mistérios e perspectivas, ou mesmo transes desconhecidos, como o que poderia instalar um caos na comunicação eletrônica, simbolizado por um bug do milênio. Momentos como este poderiam acentuar uma revalorização das questões filosóficas, em particular no campo da Filosofia Moral, onde se inserem os estudos sobre a Ética.

O estudo decorre da compreensão de que esse conhecimento, acerca de uma produção escrita na literatura periódica em Ciência da Informação e Biblioteconomia sobre a Ética e a Deontologia, trará uma contribuição relevante quanto à dimensão dos conteúdos existentes sobre o tema. Também advém da noção de que esse conhecimento poderá ser inserido de maneira mais sistemática na formação de profissionais da informação. É que esse conhecimento reuniria dois ângulos significativos, 
capazes de constituir bases relevantes para a atuação futura desses profissionais: a) evidenciaria o seu compromisso de fornecer acesso à informação aos usuários, b) e orientaria para o comprometimento com o melhor padrão de gerenciamento das unidades de informação em que tais profissionais venham a atuar.

Pode-se também reforçar a percepção de que, no período de 1997 a 2006, acentuou-se no Brasil a discussão sobre uma temática mais ampla a respeito da chamada sociedade da informação e/ou sociedade do conhecimento. Em paralelo, travou-se uma discussão que envolveu a formulação e a implantação das Diretrizes Curriculares Nacionais dos cursos de graduação em Biblioteconomia e Arquivologia. Paralelamente a esses eventos, as facilidades oferecidas pelos recursos de informação e comunicação associados à informática aceleraram o acesso da sociedade a instrumentos com potencial cada vez maior de disponibilizar a todos um incalculável conhecimento, através de um apertar de botões. Tudo isso afetou o mercado editorial, o trabalho das bibliotecas e, sobretudo, ampliou, mas também dificultou, para certas camadas da sociedade, 0 encontro das informações que atendem às suas aspirações. Torna-se compreensível, portanto, que tal conjunto de circunstâncias contribuiu para que os profissionais atuantes na produção, promoção e oferta do acesso aos conteúdos de conhecimento, procurassem formular ou rever normas de conduta profissional.

Um ambiente em que se poderia estudar essa temática é constituído pela produção editorial disponível em periódicos. Tratá-los, utilizando-os como fonte significativa para apreender o modo como abordam a Ética profissional, se torna cada vez mais urgente, para permitir o conhecimento do que está publicado e do que está disponível sobre os fundamentos filosóficos, doutrinários e temáticos; as abordagens; a presença autoral; e, sobretudo, as diferentes tendências e/ou convergências.

O material empregado para o estudo foi constituído pelos periódicos publicados no Brasil nos anos de 1997 a 2006. Consideraram-se como base para a sua seleção dois critérios: as regiões político-administrativas brasileiras e o fato de as edições referentes ao período em estudo estarem disponíveis para consulta online no momento da coleta dos dados. No Nordeste, foi identificada a revista Informação \& Sociedade: Estudos (UFPB); no Centro-Oeste a revista Ciência da Informação (IBICT); no Sudeste a revista Transinformação (PUCCAMP); e no Sul a revista Encontros Bibli (UFSC). A região Norte não foi representada no corpus selecionado, pois não dispunha de periódicos que respondessem aos critérios adotados. Para nortear o exame do material obtido nas edições em que foram colhidos artigos sobre o tema, foram empregados os termos Ética, Moral, Deontologia e Ética Profissional, buscando localizá-los nos artigos, ensaios e relatos de pesquisa encontrados. 


\section{Fundamentos conceituais do estudo}

No conhecimento humano e social de senso geral, o termo empregado para denominar um dado tema pode levar à idéia central ou a um conceito que se queira expressar. Tendo isso em vista, começa-se aqui por afirmar que o termo "Ética" levará à idéia central da Ética. A palavra "Ética" deriva do grego ethos, que significa "costume"; e a palavra "Moral", por vezes empregada como sinônimo de Ética, vem do latim mos, que também significa costume. Esse costume é resultado do valor dado às nossas atitudes; esse valor é conferido pelo homem na relação humana, de uns com os outros. A Moral é sinônimo da Ética como teoria dos costumes. Esse entendimento se reforça com a definição de Ética dada por Boff, em Ética e Moral. Para ele:

A ética é parte da filosofia. Considera concepções de fundo acerca da vida, do universo, do ser humano e de seu destino, estatui princípios e valores que orientam pessoas e sociedades. Uma pessoa é ética quando se orienta por princípios e conviç̧ões. Dizemos, então, que tem caráter e boa índole. A moral é parte da vida concreta. Trata da prática real das pessoas que se expressam por costumes, hábitos e valores culturalmente estabelecidos. Uma pessoa é moral quando age em conformidade com os costumes e valores consagrados. Estes podem, eventualmente, ser questionados pela ética. Uma pessoa pode ser moral (segue os costumes até por conveniência) mas não necessariamente ética (obedece a convicções e princípios) (BOFF, 2003, p. 37, grifos do autor).

A Ética também pode ser denominada, conforme Souza (2002), um conjunto de normas que regem a boa conduta humana. Isso estaria relacionado com a percepção que um sujeito tem e com o que sente em relação a outro ser. Significa a objetivação da noção de existência humana, que coloca o homem como conhecimento ou consciência de si próprio através do viver e do conviver, levando à construção de equilíbrio existencial, resultante de luta e cooperação. Assim também surge, neste contexto, a questão do "obrigar-se", pelo qual se considera o fato de que a promessa do cumprimento e o efetivo cumprimento dos pactos acordados estão na base do conviver. Além disso, também aparece a tolerância como um esforço humano de redução da indignidade do submeter-se, indicando que toda pessoa é livre para ter as suas próprias convicções e aceitar que os demais também tenham as suas.

A história da Ética, conforme Marcondes (2007), se entrelaça com a história da filosofia, e é nesta que ela se fundamenta, buscando contribuir para o desenvolvimento histórico e cultural da humanidade. A partir dos textos de Platão e Aristóteles, observa-se que a Ética, no Ocidente, iniciase com Sócrates. De acordo com Platão, o indivíduo que age de modo ético é aquele capaz de autocontrole, de "governar a si mesmo". Essa 
atitude só seria possível com o conhecimento desse indivíduo sobre a noção de bem, a qual é obtida por ele por meio de um longo e lento processo de amadurecimento espiritual, também dito "ascensão da alma", como descrito no Mito da Caverna. Nesse estado, o homem sairia da escuridão e passaria a enxergar todas as verdades do "mundo das idéias perfeitas".

Por outro lado, segundo a compreensão de Aristóteles, a ação correta do ponto de vista ético deve evitar os extremos, tanto o excesso quanto a falta, caracterizando-se, assim, pelo equilíbrio ou pela justa medida. Essa idéia pode ser encontrada em Ética a Nicômaco.

Mais adiante, na história ocidental, no Cristianismo de Santo Agostinho (354 a 430 a. D.) e de São Tomás de Aquino (1227 a 1274 a. D.), dois renomados doutores da Igreja Católica, surge a idéia de livre arbítrio, de "Bem e Mal". Para Marcondes (2007), São Tomás de Aquino recusa a concepção segundo a qual o "Mal" é algo, uma entidade. São Tomás o entende como parte da natureza, no sentido da imperfeição ou da corrupção das coisas criadas. Santo Agostinho, inspirado em Platão, defende que só o "Bem" existe, sendo o "Mal" apenas a ausência ou privação do "Bem". Deus, o "Ser Supremo", é sumamente bom, mas os seres criados, inferiores na ordem do "Ser", são imperfeitos e finitos, perecíveis. Daí se origina o "Mal" como falha.

A partir do século XVI, com as Revoluções Religiosas (Reforma Protestante), surge uma mais fervorosa observação dos princípios morais cristãos, tais como expressos na Bíblia. Neste período, concorre com esse estado religioso o movimento que viria a ser uma Revolução do Conhecimento. Neste âmbito, destacou-se Copérnico e sua teoria do Heliocentrismo, através da qual o Sol foi colocado no âmbito do saber professado como o centro do Sistema Solar, contrariando a então vigente teoria geocêntrica, de aceitação plena da Igreja Católica, que considerava a Terra como o centro desse sistema. Foi em meio a todas estas mudanças que também apareceram outras novas teorias, que por sua forma de expressão se colocavam em contraposição ao conhecimento escolástico, o qual representava a forma de exposição e os conteúdos aceitos pela Igreja. Dentre essas novas teorias, encontravam-se aquelas expostas através das idéias apresentadas por Descartes, em seu discurso sobre o método, em que se destacou um novo pensamento na era moderna (o Racionalismo Cartesiano), considerando a razão como o caminho para a verdade. O pensamento de Descartes era revolucionário diante da sociedade feudalista em que ele nasceu, e foi submetido à influência da Igreja Católica, que ainda era muito forte, num momento em que estava a iniciar-se a "produção de conhecimento científico". Desta forma, Descartes percebeu que os "costumes", a história de um povo e sua tradição "cultural" influenciam a forma como as pessoas pensam e aquilo em que acreditam.

Nos princípios da Era Moderna, segundo Marcondes (2007), Immanuel Kant associa à Doutrina Ética a idéia de dever. Por essa concepção, ser humano implica um ser que age racionalmente e com a convicção de estar destinado a agir bem, como um dever, pois cada um 
carrega o entendimento do que significa agir mal. Para isso, é preciso que sejam evitados os impulsos, apetites, paixões e desejos, para que se conquiste a autonomia Ética. Como explica Boff (2003, p. 43), "[...] imperativos categóricos como [esses] de Kant permaneceram, infelizmente, abstratos: 'trate o ser humano sempre como fim, jamais como meio' e 'aja de tal maneira que a máxima de sua ação possa valer como norma para todos'".

No século XIX, conforme Marcondes (2007), Friedrich Hegel expõe uma nova perspectiva, considerando o homem, a cultura e a história, destacando a noção de que a Ética é determinada por relações sociais.

De acordo com Marcondes (2007), na contemporaneidade Nietzsche atribui a origem dos valores éticos não à razão, mas à emoção. Para ele, o homem forte é aquele que não reprime seus impulsos e desejos.

Ainda sob a fundamentação teórica de Marcondes (2007), no século XX Michel Foucault defende a teoria de que a Moral não deve se reduzir a um ato ou a uma série de atos, conforme uma regra, lei ou valor. Para ele, é preciso que haja mais do que a "consciência de si", ou seja, é preciso que haja a "constituição de si" enquanto "sujeito moral". Desta forma, o indivíduo deve aprimorar-se constantemente e de acordo com seu próprio entendimento dos valores Éticos e /ou Morais. Isso implica uma atitude de permanente questionamento ou problematização.

Nos dias atuais, final do século $X X$ e início do século $X X I$, num contexto em que cada vez mais se fala de globalização, percebe-se um novo dimensionamento dessa discussão. Há várias reflexões em construção voltadas para temas mais amplos da existência, em que o ambiente e o porvir motivam o debate, como aquele promovido por Singer (1993), que leva à discussão dos direitos de todos os seres vivos de serem igualmente sujeitos de direito. Uma dessas reflexões encontra-se em Dupas (2001). Este autor afirma que não há mais espaço para uma Ética voltada para uma comunidade. A aposta é cada vez mais dirigida para o individualismo, que se manifesta no consumo e na rapidez de produção. Em lugar da felicidade pura e simples, há a obrigação do dever; para além do imperativo Kantiano, a Ética fundamenta-se em seguir normas. Trata-se de uma "Ética da Obediência", que impede o homem de pensar e descobrir uma nova maneira de se ver e, assim, encontrar uma saída em relação ao conformismo de massa, no qual se encontra a grande maioria da população. Essa idéia da subordinação e conformação, que se implantou nas últimas décadas do século $X X$, também é examinada por Flusser (1983), e constitui a temática básica da discussão de Kurz ${ }^{2}$.

Uma vertente da discussão desta temática está enfeixada pelo termo Deontologia. Trata-se de uma palavra de raiz grega, que significa "a Ciência dos Tratados". Conforme Vásquez (1996), o termo Deontologia passou a ser empregado, em 1834, por Jeremy Bentham, para referir-se ao ramo da Ética cujo objeto de estudo é o fundamento do dever, além das normas morais. A Deontologia constitui um dos dois ramos principais da Ética Normativa. Segundo Vásquez (1996), portanto, pode-se definir a

\footnotetext{
${ }^{2}$ Disponível em: <http://obeco.no.sapo.pt/>. Acesso em: 26 nov. 2009.
} 
Deontologia como o conhecimento dos deveres, tendo por base os juízos de aprovação ou desaprovação, do correto, do incorreto ou condenável, do bem ou do mal; levando em conta o ajuizamento real por parte da sociedade. Assim, ainda segundo Vásquez (1996), a Ética é o pensamento filosófico acerca do comportamento moral do homem, dos problemas morais e dos juízos morais; enquanto a Moral é o conjunto de normas, princípios e valores, aceitos ou descobertos de forma livre e consciente, que regulam o comportamento individual dos homens.

De um lado, a filosofia define "Ética" como o estudo da "conduta ideal", originada de um conceito mais amplo, o de "homem ideal". Sua missão consiste em ditar as qualidades das ações humanas, definindo-as como boas ou ruins, tendo como norte o sentido da felicidade, sintetizada na idéia do "soberano bem". Por essa perspectiva, a Ética é uma ciência que estuda os valores e virtudes do homem, estabelecendo um conjunto de regras de conduta e de postura a serem observadas para que 0 convívio em sociedade se dê de forma ordenada e justa. De outro lado, a Deontologia consiste no conjunto de regras e princípios práticos que regem a conduta de um profissional, constituindo uma ciência que estuda os deveres de uma determinada profissão.

A maioria das profissões, como a de bibliotecário, também no Brasil, construiu o seu próprio código de ética profissional com base na noção de deontologia, que, em geral, se manifesta como um conjunto de normas de cumprimento obrigatório, frequentemente incorporado à lei pública. O seu não cumprimento pode resultar em sanções impostas pela entidade de regulação, também chamada de Ordem ou Conselho profissional. Essas sanções tomam a forma de censura pública, multa, suspensão temporária ou definitiva do direito de exercer a profissão (CONSELHO FEDERAL DE BIBLIOTECONOMIA - CFB, 2002).

Pode-se afirmar, então, que a Ética profissional é produtora e é produzida em um lugar social, no qual se desenrolam as atividades executadas pelos integrantes de uma categoria profissional. Decorre isso do fato de que as profissões também são construídas e constroem socialmente a realidade, e de que a realidade se constitui por processos interacionais, conforme demonstram Berger e Luckmann (2005).

No cotidiano, as atividades elementares que os indivíduos realizam transformam lentamente a maneira como eles se comportam e sentem a realidade. As mudanças nas regras sociais e no modo como os indivíduos as percebem geram comportamentos diferentes daqueles costumeiramente observados em épocas anteriores. Modificam-se sentimentos como vergonha e medo, além de serem criadas novas concepções concernentes aos padrões de moral e costumes, de tato social, de consideração pelo próximo e de outras numerosas questões complexas. Assim, não é estranha a percepção que se tem, em geral, de que a estrutura da sociedade ocidental muda continuamente, e de que isso, simultaneamente, reforça as razões pelas quais se vêem mudanças no padrão de comportamento e da constituição psíquica dos povos dessa região do mundo. De outro lado, também se percebe a formação do poder do Estado, cuja configuração, desde o feudalismo, sofre um permanente 
aperfeiçoamento. No mesmo conjunto de fatores também se reconfiguraram os interesses econômicos e militares dessas sociedades, e assim se estabeleceu de um jeito ou modelo próximo do que hoje se conhece. Tal modelo ultrapassou a Idade Média, submeteu-se à monopolização pelos reis e sustentou o poder dos governantes no sentido de regular, organizar modalidades de exercício da autoridade e de realizar o recolhimento de tributos, baixar leis para ordenar a sociedade, formar exércitos e, em séculos mais recentes, regular o acesso aos meios de manutenção da saúde, de aquisição da educação escolar, da garantia de obtenção de trabalho, dentre outros.

Parte das condutas e sua representação de valores sobre o bem portar-se social e moral constituem normas tais como as regras de etiqueta e de boas maneiras. Pesquisas de Norbert Elias (1993), que cobrem um largo período de tempo, desde o século XIII, revelam que os hábitos ocidentais se transformaram conforme a construção social da realidade ao longo dos séculos. Da Idade Média até os dias de hoje, nossos comportamentos cotidianos foram lentamente modelados pela vida social. Desta forma, o autor explica que os costumes evoluem sempre e que todas as mudanças e alterações na constituição da sociedade implicam mudanças também na constituição psíquica do homem. Segundo o autor, esses fenômenos sociais e psíquicos podem ser descobertos com mais certeza na história da conduta humana diária.

De acordo com Elias (1993), as transações de uma fase deste processo civilizador para outra fase não podem ser determinadas com absoluta exatidão. Entretanto, observa-se que na primeira fase tratada em seu estudo, a fase medieval, época do florescimento da sociedade feudal e cortês, apresentava-se, por exemplo, o hábito generalizado de se comer com as mãos. Depois veio uma fase de mudanças muito rápidas, abrangendo os séculos XVI, XVII e XVIII, na qual se renovou o padrão de maneiras à mesa. Mais adiante, o dinheiro começou a se tornar a base das diferenças sociais, e o que as pessoas produziam e/ou realizavam tornou-se mais importante do que suas maneiras. Além das regras de etiqueta, muitas peculiaridades, como a forma de assoar, de escarrar, o comportamento no quarto, as atitudes nas relações entre os sexos, na agressividade e muitas outras, transformaram-se com o passar do tempo e transformaram o modo de agir e pensar dos indivíduos.

Uma vez que a sociedade se constrói a partir dos relacionamentos das pessoas, como explica Elias (1993), surgem questões de valor moral e ético. Por isso se pode dizer que a Ética está totalmente correlacionada com o processo de construção social, pois existe a tendência cada vez mais forte das pessoas se observarem e os demais. Essa tendência vem se acentuando depois da Idade Média, como um sinal de que o comportamento humano começou a assumir um novo caráter. O senso do que fazer e não fazer para não ofender e chocar os outros se tornou mais sutil conforme o controle das emoções, e surgiu uma postura mais pacífica e gentil no tratamento humano, pois havia a preocupação com o julgamento que os outros poderiam fazer. 
E estas transformações não param. Hoje vivemos em uma sociedade que se transforma e se renova muito mais rapidamente, através das tecnologias atuais, do acesso à informação e da formação do conhecimento. Portanto, boas práticas coletivistas dependem da intensificação discursiva. Pode-se verificar isso, conforme Bauman (2005), ao se constatar, por exemplo, que o capitalismo colonial já não sustenta mais a população inadaptada e marginalizada que o processo civilizador e o capitalismo desenvolveram. Para este autor, o grande problema do Estado é saber qual destino dar a este contingente humano tratado como "lixo", isto é, rejeito do sistema. Preocupado com tais questões sociais, Bauman (2005), no livro intitulado Vidas Desperdiçadas, faz uma abordagem da relação entre a pluralidade de pessoas e a pessoa singular (indivíduo), enxergando um novo modelo de como os seres humanos individuais ligam-se uns aos outros numa sociedade. Assim, destaca o problema da relação entre indivíduo e sociedade, demonstrando até que ponto cada pessoa é influenciada em seu desenvolvimento pela posição através da qual ingressa no fluxo do processo social. Também acentua a relevância do assunto na sociologia, fazendo um diagnóstico dos indivíduos da sociedade contemporânea que vivem sob um intenso conflito entre o individualismo e a socialização. Esses indivíduos crescem dentro de uma rede de pessoas que existia antes deles e se destinam à construção de novas redes.

Em outra vertente de análise, Bauman (2005), tanto quanto Elias (1993), fala dos problemas da autoconsciência e da imagem do homem. O autor afirma que o desejo e o medo inspiram os homens e definem sua própria formação no relacionamento entre uns e outros. Ele afirma que toda a sociedade humana consiste em indivíduos distintos, e que todo indivíduo humano só se humaniza ao aprender a agir, falar e sentir no convívio com os outros, pensando no que os outros "acham" e, por conseguinte, formando a auto-imagem e a autoconsciência. Nesse sentido, cada pessoa, ao perceber o "eu" como indivíduo e o "nós" como o eu mais os outros, constituindo família, grupo e sociedade, traz à tona, outra vez, as já apontadas questões de Ética. Assim, os homens passaram a saber que sabem, sendo capazes de pensar sobre seu próprio pensamento ao observar-se observando. Ainda conforme Bauman (2005), as mudanças na maneira como a sociedade é compreendida e até na maneira como as diferentes pessoas que formam esta sociedade entendem a si mesmas, ou seja, a auto-imagem e a composição social, não ocorrem rapidamente. Tais mudanças necessitam de várias gerações para se concretizarem, pois a subjetividade humana, apesar de sofrer transformações cada vez mais rápidas, não se transforma de uma hora para a outra, em decorrência de seu profundo enraizamento nas pessoas.

A discussão do objeto em estudo está instalada na sociedade e por essa é construída. Provavelmente, essa discussão estará também evidenciada no discurso construído e publicado nos periódicos de Ciência da Informação e Biblioteconomia. Para poder encontrar como ela se dá, necessita-se de uma metodologia apropriada. Sobre isso se falará a seguir. 


\section{Metodologia empregada}

No desenvolvimento do estudo, o processo metodológico desenrolou-se da seguinte maneira: a - pesquisa do tipo bibliográfico (quanto ao material utilizado para obter conteúdos que permitissem a formação do embasamento conceitual); b - pesquisa de tipo exploratório (quanto aos objetivos pretendidos); c - pesquisa de tipo documental (quanto à utilização das revistas tomadas como fontes básicas de coleta dos dados primários necessários ao alcance dos objetivos, ou corpus do estudo). Portanto, metodologicamente o trabalho envolveu: a identificação dos periódicos e dos textos publicados sobre a temática; a leitura e a descrição dos textos; a identificação das temáticas, das abordagens, dos fundamentos filosóficos e doutrinários e das tendências da discussão sobre a Ética na produção periódica de Biblioteconomia e Ciência da Informação, editada no período de 1997 a 2006; a análise dos discursos segundo a Técnica do Discurso do Sujeito Coletivo, explicitada mais adiante; e a organização das idéias contidas visando à elaboração de uma síntese.

Para a realização da pesquisa, foram escolhidas as revistas de Biblioteconomia/Ciência da Informação listadas a seguir, considerando-se que oferecem acesso eletrônico/digital a seu conteúdo e segundo a região político-administrativa brasileira em que estão sediadas: Informação \& Sociedade: Estudos (UFPB), do Nordeste; Ciência da Informação (IBICT), do Centro-Oeste; Transinformação (PUCCAMP), do Sudeste, e Encontros Bibli (UFSC), do Sul. A ausência de representação da região Norte foi devida à inexistência de periódico de Biblioteconomia/Ciência da Informação que responda aos critérios estabelecidos. Para preparar a etapa de pesquisa bibliográfica, efetuou-se o levantamento dos títulos de livros que continham conteúdo referente às correntes filosóficas da Ética, conteúdo relevante para a construção de uma síntese histórica de caráter doutrinário. Desta forma, foram localizados os títulos que compõem as referências finais deste artigo. Também foi realizada a leitura com o emprego de um sistema de fichamento das idéias e, posteriormente, foram elaboradas as fichas (de citação, de resumo de linhas teóricas e de opinião) pertinentes ao tema do projeto científico. Mais adiante, através dos campos de busca das revistas eletrônicas, foi possível recuperar os artigos, ensaios e relatórios de pesquisa que apresentavam os termos escolhidos a priori (Ética, Moral, Deontologia e Ética Profissional), tendo sido encontrados dez documentos sobre o assunto. Sete foram publicados na revista Ciência da Informação e os outros três nas outras revistas, sendo um em cada uma. Esses documentos, a fim de respeitar o critério de não identificação dos autores na apresentação dos resultados e em sua interpretação, foram codificados com o uso de letras do alfabeto.

$\mathrm{Na}$ preparação e realização das atividades da etapa de pesquisa documental, cujo detalhamento está ampliado no próximo tópico deste artigo, foi empregado um formulário de coleta de dados. Nele, foi feita a anotação de dados de identificação dos documentos que constituíram o 
corpus do estudo, considerando-se: o ISSN da revista, a referência, as palavras-chave e o resumo de cada texto.

Na realização desta etapa foram utilizadas algumas normas da ABNT - NBR 6023:2002 (NB 66) Referências; NBR 6028:03 (NB 88) Resumo; NBR 6027:2003 (NB 85) Sumário; NBR 14724:2005 Trabalhos acadêmicos; NBR 15287:2005 Projeto de pesquisa; NBR 10520:2002 (NB 896) Citações -, a fim de dar uniformidade aos dados coletados. Ainda nesta fase da pesquisa, foram anotadas certas peculiaridades que 0 Glossário de Biblioteconomia e Ciências Afins (ARRUDA; CHAGAS, 2002) pôde esclarecer, além de algumas leituras sobre abordagens metodológicas, tais como a do trabalho de Oliveira (1998), que trata das metodologias das Ciências Humanas; de Teixeira (2005), sobre as três metodologias - acadêmica, da ciência e da pesquisa; e de Eco (2004), que aborda os limites da interpretação; o que auxiliou no processo de desenvolvimento da pesquisa e na forma de apresentação de seus resultados.

Para a realização do estudo, foi empregado um instrumental que permitiu a coleta dos dados textuais e o tratamento dos mesmos. A técnica escolhida foi a do Discurso do Sujeito Coletivo, formulada por Lefèvre e Lefèvre (2005), a qual vem sendo empregada em outros trabalhos já realizados e em realização no Grupo de Pesquisa Informação, Tecnologia e Sociedade, do Departamento de Ciência da Informação da UFSC. Esta técnica consiste na classificação dos dados levantados em categorias de análise denominadas: Expressão Chave (ECH), Idéia Central (IC) e Ancoragem (AC). Uma vez identificadas e registradas as $\mathrm{ECH}$, que são constituídas por trechos de cada texto analisado relevantes para 0 tema da pesquisa; e uma vez destacadas as IC, que representam a descrição mais sucinta e objetiva possível daquilo que trata o documento e que são extraídas a partir da $\mathrm{ECH}$, passou-se para a identificação e recomposição dos eixos integradores de um ou mais DSC contido no corpus em estudo. Nessa etapa, considerou-se a possível ocorrência de idéias centrais semelhantes ou complementares no conjunto desse corpus. Desta forma, foi possível individualizar dois eixos discursivos, descrevendo positivamente suas especificidades semânticas, para poder distingui-los entre si. Assim, enquanto a IC sintetizou o discurso, as ECH apresentaram o conteúdo e/ou a substância desse discurso, evidenciando dois Discursos Coletivos existentes nos textos que compuseram o corpus do estudo. As ICs e as ECHs, tomadas como dispositivos metodológicos, mostram-se adequadas para levar ao entendimento e à descrição dos sentidos dos discursos, de modo que a IC identifica, particulariza e especifica o discurso, enquanto as ECH corporificam tais discursos. Além disso, algumas $\mathrm{ECH}$ remetem a uma $\mathrm{AC}$, tornando-se possível identificar a base teórica, ideológica ou a crença que o autor do discurso professa por trás do mesmo; isto é, onde o seu discurso está ancorado. Na elaboração deste artigo, a AC corresponde ao que foi verificado no corpus examinado em relação à orientação doutrinária da Ética.

Esse instrumental e o processo aqui descrito serviram como auxílio metodológico em todo o desenvolvimento da parte empírica da pesquisa, 
desde a coleta dos dados até sua posterior análise e apresentação dos resultados, objetivados nos dois Discursos Coletivos encontrados durante a análise do material. Esses discursos representam a reunião dos dois principais conjuntos de idéias que se destacaram no processo de análise. Cabe afirmar que o DSC é uma síntese que agrega todas as idéias apresentadas na conversação ou no conjunto da documentação tratada, independentemente da freqüência de sua manifestação. A relevância é dada à emergência da idéia no conjunto de discursos. Naturalmente, o corpus da pesquisa teve como base a noção de que os discursos localizados nos textos examinados partiram de uma motivação comum: a veiculação de um tema em periódico de um campo específico de conhecimento por meio de textos cuja publicação foi aprovada por uma mesma comunidade científica, que constitui o corpo editorial permanente ou "ad hoc" desses periódicos. Os dois discursos coletivos obtidos compõem o teor da seção seguinte. Em um desses discursos, está evidenciada a explicitação de fundamentos, conceituações ou ações suportadas por doutrinas éticas, e no outro estão expostas as opiniões dos seus autores sobre a conduta profissional num contexto social profundamente penetrado pela tecnologia.

\section{Resultados e interpretação}

Os textos obtidos nos periódicos foram submetidos a uma primeira leitura. Nessa leitura fez-se o reconhecimento dos objetivos expressos e implícitos, do tipo de texto (científico, ensaístico, etc.), da fundamentação teórica predominante, de sua estrutura e extensão, e dos resultados e/ou conclusões expostos pelo (a) autor (a). Por último, arrolou-se a literatura empregada como suporte bibliográfico em cada um, compondo uma lista final da bibliografia evidenciada nessa produção.

Foi feita uma segunda leitura de cada texto, com o propósito de se extrair as Expressões-chave $(\mathrm{ECH})$ neles contidas que trouxessem a explicitação de potencial resposta para os termos de pesquisa adotados neste estudo. Fez-se o devido registro destas $\mathrm{ECH}$ em planilha desenhada e empregada para essa finalidade. Essa planilha continha duas colunas básicas: a primeira para o registro das Expressões-chave e a segunda para o registro das Idéias centrais (IC). Em seguida, foi realizada a leitura das $\mathrm{ECH}$, para nelas identificar e anotar na coluna dois da planilha já referida os termos identificados como IC. Concluída a etapa de exploração do texto, foi feito o agrupamento das $E C H$, a partir das IC que apresentaram semelhanças temáticas, a fim de se organizarem os Discursos Coletivos evidenciados no material analisado. Para isso, trabalhou-se com a idéia de eixos integradores. Foram, então, identificados dois eixos: a) de explicitação de fundamentos, conceituações ou ações suportadas por doutrinas éticas; e b) de exposição de opiniões dos autores dos textos sobre a conduta profissional num contexto social profundamente penetrado pela tecnologia.

A perspectiva do encontro desses eixos integradores tem o propósito de se evitar uma dispersão de discursos, o que poderia dificultar uma 
interpretação com maior carga de sentido. Esses eixos integradores decorrem de uma escolha do pesquisador a partir das idéias contidas no material analisado. Nessa circunstância, o pesquisador está motivado pela tentativa de propor uma conclusão que reflita uma melhor compreensão do que há de mais expressivo nas opiniões localizadas nos discursos examinados, como se fosse a produção de um único autor, um autor coletivo. Os resultados alcançados não são obtidos por critérios estatísticos. A abordagem feita representa uma busca do significado que esses eixos integradores, que dão a base para a expressão dos DSC identificados, têm para os proferentes dos discursos que contêm aquelas idéias ou representações, quando vistos como fala de um coletivo constituído na circunstância tomada para análise. Em outros termos, o Discurso do Sujeito Coletivo reúne a essência do pensamento explicitado no corpus utilizado.

Assim, o esforço de pesquisa caminha no sentido de que não se realize intervenção sobre os textos examinados. Quando necessário, especialmente em coleta de entrevistas, os silêncios ou uma súbita mudança na explicitação da idéia por parte do respondente podem requerer a inclusão de conectivos (para, e, ou...), a fim de tornar o texto mais fluente, desde que isso não modifique os pensamentos recolhidos. No caso do estudo em foco, realizado sobre textos já publicados, não foi necessária a adoção dessa providência. Nos tópicos 4.1 e 4.2 estão apresentados os DSC compostos pelos dois eixos integradores localizados quando da análise do material coletado.

\section{DSC 1 [fundamentos, conceituações ou ações suportadas por doutrinas éticas]}

"A antiga sociedade disciplinar, característica do capitalismo de produção centrada na exploração do trabalho industrial está sendo substituída por uma sociedade de controle, que traz à tona um capitalismo de circulação e de comunicação originado na esteira das mutações tecnológicas da era da informatização planetária, legitimada pelo discurso neoliberal guiado pelo mercado. Após ter sido "docilizado" nos processos de industrialização, o corpo social terá que inventar novos valores, com regras facultativas que permitam criar no heterogêneo sem a preocupação com identidades definidas de uma vez por todas, nas instâncias múltiplas da alteridade e da pura diferença. Eis um caminho para pensar a Ética. A Ética em sua essência é uma meta desejável da representação de valor, da Moral, da honra, do direito à cidadania, da justiça, da cultura, da linguagem, do conhecimento, do estágio técnico-científico, do pensamento e de outros comportamentos e ações individuais e/ou coletivas, privadas e/ou institucionais. A relevância das considerações sobre Ética e cidadania está, nos dias atuais, no sentido de se buscar compreender sua estreita vinculação com o sentido de solidariedade. É preciso, então, conhecer-se e saber que se sabe, ações que constituem a essência da Ética, que, por sua função reflexiva, interpreta, perscruta, compara, pondera e integra a razão com sensibilidade e equilíbrio. Como auto-apropriação, torna-nos 
aptos às mais diversas atividades do espírito humano. A experiência humana, assim refletida, ultrapassa as fronteiras do raciocínio lógico formal para explorar o território misterioso do sentido da existência e elaborar a história e o mundo como sistemas em que podemos iniciar nossos próprios processos e empreender nossa ação, o que acaba por constituir uma mediação para a nossa liberdade. Isso faz perceber que não é o conhecimento que nos compromete, mas o conhecimento do conhecimento, entendido como a Ética que permitirá aperfeiçoar o pensamento reflexivo como instrumento de emancipação humana, até porque é a ignorância dessa condição que deflagra a maior parte dos problemas do mundo. A Ética é uma característica inerente a toda ação humana e, por essa razão, é um elemento vital na produção da realidade social. A Ética está relacionada à opção, ao desejo de realizar-se na vida e de manter com os outros relações justas e aceitáveis. A vida Ética consiste na interiorização dos valores, normas e leis de uma sociedade, condensados na vontade objetiva cultural, por um sujeito moral que as aceita livre e espontaneamente, através de sua vontade subjetiva individual; vale dizer, é a aceitação harmoniosa da vontade coletiva de uma cultura que, com o passar do tempo, se concretiza e se fortalece dentro de uma sociedade, em especial, no âmbito das profissões. Vista como prática, é no exercício de uma Ética do Discurso que o direito ao acesso à informação e o direito de se expressar, bem como o respeito aos Direitos Humanos, aparecem como imperativos. A Ética do Discurso trata as questões da conduta, ou Moral, de forma procedimentalista; leva em conta a vida cotidiana em seu fluxo atual, ela não é uma Ética que pode ficar congelada no tempo (15 anos, por exemplo!); trabalha sobre critérios ou procedimentos de validação das normas geradas no cotidiano; leva em conta a igualdade e universalidade discursiva que envolve todos os afetados, por exemplo, fornecedores de serviços e usuários; leva em conta a existência de sujeitos plenos de conhecimento e capacidade de decidir através da ação comunicativa. Pela vertente procedimental constituem-se as Comissões de Ética. Para isso, algumas condições são necessárias para que elas possam atuar de modo proveitoso: a) Que sejam estabelecidas regras de participação ou de funcionamento interno da Comissão; b) Que seja assegurada a independência da Comissão; c) Que a organização assuma o compromisso expresso de apoio à Comissão; d) Que se entenda a Comissão, não somente como um órgão reativo, isto é, que responde a problemas levantados por outros, mas que tenha papel ativo na proposição de ações e iniciativas; e e) Que a Comissão tenha a capacidade de fazer valer suas decisões. Destacam-se duas matrizes de discurso ético na prática bibliotecária. Numa perspectiva, a Prescritiva, 0 Estado dita a atuação profissional e controla suas práticas diretamente, que é o caso brasileiro. Na outra perspectiva, a Procedimental, o Estado concede a prática para a categoria, que corre todos os riscos do compromisso que assume com a sociedade; é o que ocorre nos EUA". 


\section{DSC 2 [conduta profissional num contexto social profundamente penetrado pela tecnologia]}

"No caso do bibliotecário brasileiro, coloca-se como uma necessidade atual, mais forte do que em qualquer outro momento, o exame do seu discurso ético. Isso se dá justamente pelo fato de nesse país se estar vivendo uma forte mudança dos parâmetros de atuação profissional, seja tanto por razões econômicas quanto por razões sociais e políticas. Há uma falta de sintonia entre o discurso ético oficial da categoria bibliotecária brasileira e o seu discurso corrente sobre as práticas profissionais. Há a necessidade de melhorar conhecimentos, competências e técnicas em uma proposta que leva ao desenvolvimento intelectual dos membros do grupo. Há a necessidade da própria categoria se conhecer melhor e conhecer a sociedade na qual se situa para não ignorar o outro, para não ignorar a dimensão social do ser humano. No mundo atual, muitas profissões elaboraram diretrizes éticas, com o objetivo de orientar aqueles que as exercem. A Biblioteconomia, não constituindo exceção à regra, procurou garantir à sociedade, por meio da criação de princípios éticos biblioteconômicos, que as atividades desenvolvidas por seus profissionais não representem interesses pessoais, mas sim, signifiquem uma efetiva contribuição à coletividade. A cautela existente é justificada, acima de tudo, pela necessidade de encontrar soluções que preservem os aspectos legais e éticos envolvidos principalmente na distribuição de documentos, até que surja uma nova ótica destes problemas. Nesse contexto, a tecnologia de produção de documentos digitais desenvolveu-se mais rapidamente do que instrumentos legais para protegê-la e isso é fato. A tecnologia é um catalisador de mudanças particularmente importantes e pungentes para as bibliotecas, uma vez que cria novas necessidades e altera velhos e sólidos paradigmas estabelecidos ao longo de muitos séculos. A decorrência maior desta transição é que a informação torna-se cada vez menos ligada ao objeto físico que a contém. As poucas décadas de tecnologia digital já estão provocando transformações aceleradas. Começa a despontar um novo ecossistema informacional em que a relação entre autores, leitores, editores (publicadores), bibliotecas e livrarias torna-se menos precisa e está em constante transformação. Assim, tanto a conquista de direitos políticos, civis e sociais, quanto a implementação dos deveres do cidadão dependem do livre acesso à informação sobre tais direitos e deveres. Existem direitos e deveres a serem cumpridos pelos cidadãos, pois constitui uma questão Ética oferecer oportunidade a todos, tais como o livre acesso às informações, incluindo o direito à inclusão digital. Nesse ambiente, cabe pensar em políticas de informação e para que se possa pensar em políticas de informação precisamos compreender para quem vamos defini-la. Importa saber também com qual intensidade, multiplicidade e pluralidade nós poderemos propor caminhos que venham a incluir, fortalecer e dar oportunidades aos que se encontram fora das cadeias de produção, mas que paradoxalmente nada sabem fazer com o 
tempo livre. Está aí a ciência da informação, ela representa o núcleo básico das ciências da vida, considerando-se que ela aborda toda a diversidade dos valores culturais do homem e da sociedade, uma vez que a moral humana desconhece ficções. Assim, a Ciência da Informação, além de ter o compromisso com a disseminação e socialização da informação em cumprimento da lei, tem o valor de um bem cultural da sociedade e, ainda, entre os seus infinitos atributos, o de resgatar a diversidade cultural do nosso processo civilizador. Os problemas de informação não podem ser abordados dentro de apenas uma área da atividade científica. É necessário o desenvolvimento de abordagens teóricas e metodológicas que favoreçam a interdisciplinaridade e permitam o relacionamento da Ciência da Informação com outros campos científicos. A informação, quando adequadamente assimilada, produz conhecimento, modifica o estoque mental de saber do indivíduo e traz benefícios para seu desenvolvimento e para o bem-estar da sociedade em que ele vive".

\section{Uma leitura interpretativa a partir da análise e síntese do corpus utilizado}

Embora a abordagem predominante neste estudo não tenha cunho quantitativo, nesta etapa de interpretação serão feitas menções dessa ordem, apenas com o sentido de deixar explícito que o DSC não visa encontrar e apresentar textos que sejam unânimes quanto às idéias neles contidas. No DSC, visa-se identificar o que foi dado como opinião ou representação de idéias dentro de um dado contexto de realidade social.

Destaca-se que dois artigos componentes do corpus estudado deixam expressamente claras as Doutrinas e/ou Correntes Éticas que serviram de fundamentação teórica para a elaboração dos mesmos. No primeiro, estavam explícitas a Ética do Discurso, interpretável segundo o modo como a explica HERRERO (2000), e a Ética da Alteridade, interpretável segundo o modo como a explica PIVATTO (2000). No outro, a Ética do Discurso. Fica claro, no primeiro artigo, que a proposta de uma Ética da Alteridade implica a idéia de uma relação responsável, na qual o outro não é tomado como objeto e em que se extingue a possibilidade de dominação. Ressalta-se, ainda, que é no exercício de uma Ética do Discurso que o direito ao acesso à informação e o direito de se expressar, bem como o respeito aos direitos humanos, aparecem como imperativos para a realização de uma Ética do Discurso. No segundo artigo, seu autor aborda a Ética do Discurso, destacando a forma "Procedimentalista" das questões da conduta, ou Moral. Essa abordagem ajuda na reflexão sobre uma possível reconstrução do discurso ético do bibliotecário brasileiro, para que este discurso seja mais compatível com o discurso profissional. Além disso, o segundo texto trata também dos fundamentos éticos. Conforme o autor, existem fundamentos explicativos para o estudo ou o reconhecimento da evolução do saber ético, a partir de seis linhas doutrinárias: o Intelectualismo Moral, o Eudemonismo, o Hedonismo, a Ética Cristã, o Emotivismo e a Ética formal ou autônoma. 
No entanto, é possível identificar algumas ancoragens doutrinárias em outros dos dez artigos estudados na pesquisa. A própria Ética do Discurso aparece novamente em outro texto. Nele, é destacada a questão da reflexão e da liberdade do pensamento, e do direito de formular um discurso, ao defender que a capacidade humana de leitura não se prende apenas em um raciocínio lógico e formal, uma vez que ao se ter acesso à informação, pode-se produzir conhecimento. Defende-se também a idéia da racionalidade discursiva.

Um outro texto revela um embasamento teórico na Corrente da Ética da Alteridade e da Ética do Discurso. Destaca que a vida Ética consiste na interiorização dos valores, normas e leis de uma sociedade, através da aceitação harmoniosa da vontade coletiva de uma cultura que, com o passar do tempo, se concretiza e se fortalece dentro de uma sociedade, através de um entendimento mútuo, portanto, do discurso proferido.

Em outro artigo, aparece claramente a Doutrina da Teoria Éticopolítica da Justiça, interpretável segundo o modo como a explica FELIPE (2000). O texto trata da questão da inclusão digital e do modo como esta deve ser analisada, sendo considerada uma ação que promoverá a conquista da "cidadania digital" e contribuirá para a inclusão social. Os autores dizem que tanto a conquista de direitos políticos, civis e sociais, quanto a implementação dos deveres do cidadão, dependem do livre acesso à informação.

Há, também, dois textos que abrangem a Ética do Discurso e a idéia de garantia da liberdade e dos direitos do discurso. No primeiro caso, há a defesa de tais direitos discursivos, independente de seus formatos. Esse artigo trata do formato virtual. Desta forma, fala-se da Ética na distribuição de documentos, ao afirmar que a tecnologia de produção de documentos digitais desenvolveu-se mais rapidamente do que os instrumentos legais para protegê-la. No segundo texto, são abordados os casos de fraude, plágio e outros tipos de conduta inadequada no processo de produção e comunicação da ciência, que se repetem com freqüência crescente nas comunidades científicas.

Em outro artigo, seu autor adentra a Teoria Ético-política da Justiça e alerta para o fato de que precisamos pensar em políticas de informação para o próximo século, o XXI, e que precisamos compreender para quem vamos defini-la, destacando ainda uma ancoragem na Doutrina Ética para a Civilização Tecnológica - interpretável segundo o modo como a explica GIACOIA (2000) - e na responsabilidade com a natureza que a sociedade tecnológica destrói.

Um dos artigos aborda um pouco cada uma das várias Doutrinas: a Ética do Discurso, quando se refere à linguagem; a Ética da Alteridade, no que diz respeito ao humanismo sem individualismo; a Ética do Utilitarismo, interpretável segundo o modo como a explica CARVALHO (2000) e o desejo da felicidade, além da Teoria Ético-política da Justiça, ao destacar o direito à justiça e à cidadania.

Outro artigo propõe a retomada da "responsabilidade social" como fundamento à práxis dos cientistas da informação e como "padrão que 
une" ciência e Ética, no campo da Ciência da Informação; demonstrando uma fundamentação na Ética da Alteridade e na Ética do Utilitarismo, que prevê a promoção da felicidade, diz não à miséria e ao sofrimento e ressalta a busca pelo prazer e pela felicidade (Hedonismo e/ou Eudemonismo).

No conjunto dos artigos examinados, destacam-se como fundamentos éticos, como se pode perceber no DSC1, as Doutrinas da Ética do Discurso, da Ética da Alteridade e da Teoria Ético-política da Justiça, que foram as mais adotadas pelos autores e que serviram de embasamento teórico na formação das suas opiniões. Quanto às temáticas e abordagens, e às tendências da discussão Ética na produção periódica brasileira de Biblioteconomia e Ciência da Informação, conforme evidenciado no DSC2, é tratada a questão da postura profissional, que também é determinada pelo quadro atual da sociedade e das novas tecnologias em desenvolvimento contínuo. Isso diz respeito, inclusive, à postura de tais profissionais para resolverem problemas decorrentes do avanço tecnológico. Todas estas temáticas se referem à sociedade e, portanto, aos profissionais da informação. São questões pertinentes e talvez devam ser inseridas nas discussões relativas ao processo de formação de tais profissionais. Certamente uma formação humanista, que insira mais conhecimentos sobre tais problemas, poderá prover os meios para a realização das reflexões necessárias acerca de suas responsabilidades e, assim, ajudá-los a desenvolver um trabalho conscientemente ético, que auxilie no progresso da sociedade.

\section{Conclusão}

Os resultados da pesquisa, mostrados em parte neste artigo, foram obtidos a partir da análise de uma temática que, embora reconhecida como relevante, no Brasil, mantém-se pouco explorada na literatura periódica de Biblioteconomia e Ciência da Informação. Isso é, de certo modo, contrastante com o fato de que, no país, na década de 1960, a categoria de profissionais bibliotecários dispôs em um Código de Ética os critérios de orientação de sua conduta profissional. A relevância da Ética apenas como instrumento de regulação da conduta profissional não tem feito com que se trate mais frequentemente desse tema nos veículos examinados. Foi evidenciada, neste estudo, a ausência de publicação de textos em alguns dos anos do período considerado, em periódicos que estavam abertos, nesse período, à aceitação da temática, e que compõem o conjunto de fontes de difusão reconhecidas pela comunidade acadêmica brasileira da área de Ciência da Informação e Biblioteconomia.

Quanto às Doutrinas e/ou Correntes da Ética Contemporânea, identificadas nos dez artigos apreciados, percebe-se que existe preocupação com o tema Ética por parte de alguns profissionais da informação que escrevem e publicam sobre 0 assunto. Foram identificadas, como fundamentos éticos de seus discursos, as Doutrinas da Ética do Discurso, da Ética da Alteridade e da Teoria Ético-política da Justiça; como também foram identificadas as temáticas, abordagens e 
tendências da discussão Ética. O discurso sobre a Ética expressa a questão da postura profissional determinada pelo quadro atual da sociedade e pelas tecnologias em desenvolvimento contínuo. Expõe também o pensamento sobre a postura dos profissionais para resolverem problemas decorrentes do avanço tecnológico.

\section{Corpus da pesquisa}

COSTA, I. T. M. Informação, trabalho e tempo livre: políticas de informação para o século XXI. Ciência da Informação, Brasília, v. 28, n. 2, p.136-138, mai./ago. 1999.

FREIRE, I. M. O olhar da consciência possível sobre o campo científico. Ciência da Informação, Brasília, v. 32, n. 1, p. 50-59, jan./abril. 2003.

GASQUE, K. G. D.; TESCAROLO, R. Sociedade da aprendizagem: informação, reflexão e ética.Ciência da Informação, Brasília, v. 33, n. 3, p. 35-40, set./dez. 2004.

LEVACOV, M. Bibliotecas virtuais: ( $r$ )evolução? Ciência da Informação, Brasília, v. 26, n. 2, p.125-135, maio/ago. 1997.

MISCHIATI, A. C.; VALENTIM, M. L. P. Reflexões sobre a ética e a atuação profissional do bibliotecário. Transinformação, Campinas, v. 17, n. 3, p. 210-218, set./dez. 2005.

PESSANHA, C. Critérios editoriais de avaliação científica: notas para discussão. Ciência da Informação, Brasília, v. 27, n. 2, p. 226-229, maio/ago. 1998.

PRADO, G. M. Da ordem presente à razão futura : alguns pontos de vista sobre o tema Ética na produção científica do IBCT (1972-1996). Ciência da Informação, Brasília, v. 25, n. 3, p. 319-329, set./dez. 1997.

RASCHE, F. Questões éticas para bibliotecários. Encontros BIBLI, Florianópolis, n. 19, p. 21-33, 1. sem. 2005.

SoUZA, F. C. de. Conduta profissional, discurso ético e ética do discurso na biblioteconomia. Informação \& Sociedade, João Pessoa, v. 15, n. 1, p. $1-14,2005$.

SILVA, H. P. et al. Inclusão digital e educação para a competência informacional: uma questão de ética e cidadania. Ciência da Informação, Brasília, v. 34, n. 1, p. 28-36, jan./abr. 2005.

\section{Referências}

ARRUDA, S. M.; CHAGAS, J. Glossário de biblioteconomia e ciências afins. Florianópolis, SC: Cidade Futura, 2002.

ASSOCIAÇÃO BRASILEIRA DE NORMAS TÉCNICAS (ABNT). NBR 6023: informação e documentação: referências: elaboração. Rio de Janeiro, 2002. 
. NBR 6024: informação e documentação: numeração progressiva em documento escrito: apresentação. Rio de Janeiro, 2003.

. NBR 6027: informação e documentação: sumário: apresentação. Rio de Janeiro, 2003.

Janeiro, 2003.

NBR 6028: informação e documentação: resumos. Rio de

- NBR 10 520: informação e documentação: citações em documentos: apresentação. Rio de Janeiro, 2002.

NBR 14 724: informação e documentação: trabalhos acadêmicos: apresentação. Rio de Janeiro, 2005.

BAUMAN, Z. Vidas desperdiçadas. Rio de Janeiro: Jorge Zahar, 2005.

BERGER, P.; LUCKMANN, T. A construção social da realidade. $25^{a}$. ed. Petrópolis, RJ: Vozes, 2005.

BOFF, L. Ética e moral: a busca dos fundamentos. Rio de Janeiro: Vozes, 2003. 125 p.

CARVALHO, M. C. M. Por uma ética ilustrada e progressista: uma defesa do utilitarismo. In: OLIVEIRA, M. A. (Org.).Correntes fundamentais da ética contemporânea. 2. ed. Petrópolis: Vozes, 2000. p. 99-118.

CONSELHO FEDERAL DE BIBLIOTECONOMIA. Resolução CFB n.0 42 de 11 de janeiro de 2002. Dispõe sobre o Código de Ética do Conselho Federal de Biblioteconomia. Disponível em: <http://www.cfb.org.br/UserFiles/File/Legislacao/Resolucao/Resolucao_04 2-02.pdf>. Acesso: 14 ago. 2009.

DUPAS, G. Ética e poder na sociedade da informação. 2. ed. São Paulo: Editora UNESP, 2001.

ECO, U. Os limites da interpretação. 2. ed. São Paulo: Perspectiva, 2004.

ELIAS, N. O processo civilizador: uma história dos costumes. Rio de Janeiro: Jorge Zahar Ed, 1993. v. 1. 271p.

- O processo civilizador: formação do estado e civilização. Rio de Janeiro: Jorge Zahar, 1993. v. 2. 307p.

FELIPE, S. Rawls: uma teoria ético-política da justiça. In: OLIVEIRA, M. A. (Org.).Correntes fundamentais da ética contemporânea. 2. ed. Petrópolis: Vozes, 2000. p. 133-162.

FLUSSER, V. Pós-história. São Paulo: Duas Cidades, 1983.

GIACOIA, O. J. Hans Jonas: O princípio responsabilidade. In: OLIVEIRA, M. A. (Org.).Correntes fundamentais da ética contemporânea. 2. ed. Petrópolis: Vozes, 2000. p.193-206.

HERRERO, F. J. Ética do discurso. In: OLIVEIRA, M. A. (Org.).Correntes fundamentais da ética contemporânea. 2. ed. Petrópolis: Vozes, 2000. p. 163-192. 
LEFÈVRE, F.; LEFÈVRE, A. M. C. Discurso do sujeito coletivo. 2 ed. Caxias do Sul: Educs, 2005.

MARCONDES, D. Textos básicos de ética de Platão a Foucault. Rio de Janeiro: Jorge Zahar, 2007.

OLIVEIRA, P. S. (Org.). Metodologia das ciências humanas. São Paulo: Hucitec/UNESP, 1998.

PIVATTO, P. S. Ética da alteridade. In: OLIVEIRA, M. A. (Org.).Correntes fundamentais da ética contemporânea. 2. ed. Petrópolis: Vozes, 2000. p. 79-98.

SINGER, P. Ética prática. São Paulo: Martins Fontes, 1993.

SOUZA, F. C. Ética e deontologia: textos para profissionais atuantes em bibliotecas. Florianópolis: EDUFSC; Ed. UNIVALI, 2002.

TEIXEIRA, E. As três metodologias: acadêmica, da ciência e da pesquisa. Petrópolis, Rio de Janeiro: Vozes, 2005.

VÁZQUEZ, Adolfo S. Ética. 16 ed. Rio de Janeiro: Civilização Brasileira, 1996. 